\title{
HOME BASED CARE FOR PEOPLE LIVING WITH HIV/AIDS; ASSESSMENT OF KNOWLEDGE, ATTITUDE AND PRACTICE AMONG FAMILY CARE GIVERS AT UKONGA WARD IN ILALA DISTRICT
}

\author{
MALALE, KIJA (BSCN 4)
}

\section{Executive summary}

Background: For many AIDS patients in low income countries such as African countries (Tanzania), hospital care is not always affordable or accessible and home-based care services rarely exist as a solution for meeting needs of PLWHA.

Objective: To assess the knowledge, attitude and practice of home based care among family care givers for PLWHA.

Setting: Study was conducted at Ukonga ward in Ilala District, Dar es Salaam with family care givers who accepted to participate in the study.

Methods: A cross sectional descriptive study design was used: Convenience sampling was used in recruiting the family care givers who had ever provided or were at that time providing care to PLWHA at Ukonga ward.

Results: 103 Family Care givers participated in this study; 73(71\%) were female and 30(29\%) were male. The mean age of participants was 38 years. The study revealed that $17 \%$ believed that they were knowledgeable, 65(63\%) had inadequate knowledge and 21( 20\%) had no knowledge whatsoever of HBC for PLWHA.. The relationship of believed knowledge and hospital re-admission of PLWHA was not statistically supported $(\mathrm{P}<0.001, \mathrm{P}=0.0096$ and $\mathrm{P}=0.0206$ for those who believed that were knowledgeable, had less knowledge and had no knowledge respectively). 86(83\%) reported that home is a better place than hospital in caring for PLWHA, and the relationship with hospital re-admission was not significance supported $(\mathrm{P}=0.2629), 55(53 \%)$ reported to have had good practice of Home-Based Care for their patients. The relationship of poor practice of Home Based Care and hospital re-admission of PLWHA was statistically not supported $(\mathrm{P}=0.61762)$.

Conclusions and recommendation: The study highlighted that majority of family care givers believed they had inadequate knowledge, had a good attitude and practice of the HBC provision. Therefore HBC Training is important for family members who are taking care of their relatives living with HIV/AIDS and further studies should be conducted in order to explore reasons as to why there is prevalence of hospital re-admission among PLWHA in developing countries like Tanzania.

\subsection{INTRODUCTION AND BACKGROUND}

According to the World Health Organization (WHO), home based care (HBC) is any form of care given to ill people in their homes. Such care includes physical, psychosocial, palliative and spiritual care. Psychosocial support may address such issues as stigmatization, depression and isolation, which prevent PLWHA from seeking treatment and support. Palliative care addresses the components of pain, illness, and infection management. The goal of $\mathrm{HBC}$ is to provide hope through high-quality and appropriate care that helps ill people and families to maintain their independence and achieve the best possible quality of life ${ }^{(1)}$.

The Home-Based Care (HBC) concept is 
an innovative approach to comprehensively meeting the needs of People Living with HIV/ AIDS (PLWHA) in resource-limited settings. It bridges the gap between health facilities and home care by enabling PLWHA to receive quality and dignified services in their homes, most often provided by family members ${ }^{(2)}$.

For many AIDS patients in low income countries such as in Africa e.g. Tanzania, hospital care is not always affordable or accessible and homebased care services rarely exist ${ }^{(3)}$. The increasing number of AIDS patients that are occupying hospital beds calls for an alternative way of providing health care. In Tanzania about 50-60\% of hospital medical-ward bed occupancy is due to HIV/AIDS ${ }^{(4)}$. Most often the care for AIDS patients falls on family members, especially on women and girls ${ }^{(5,6)}$. Community home based care (CHBC) provided in the home as part of an integrated approach in the care, support and treatment of HIV/AIDS, involves a variety of services, provided primarily by an organization such as Non-Governmental Organizations (NGO's), Faith-Based Organizations (FBO's) And Community-Based Organizations (CBO's) which is linked to various facilities and or groups.

Recent statistics indicate an alarming rate of readmission to hospital of patients with numerous complications, suggesting poor quality care in homes due to increased burden of care for PLWHA by the women and girls ${ }^{(5,6,7)}$.This study focused on assessment of knowledge, attitude and practice of $\mathrm{HBC}$ among family caregivers for PLWHA to see if there is an association of poor knowledge, attitude and practice of $\mathrm{HBC}$ among family care givers and hospital re-admission.

\subsection{METHODOLOGY}

\subsection{DESIGN}

A cross-sectional descriptive study design was used to assess the knowledge, attitude and practice of Home Based Care among family caregivers for PLWHA. A quantitative method was used for exploring the demographic personal data, knowledge, attitude and practice of home based care among the respondents.

\subsection{STUDY POPULATION}

The target population was family caregivers who had ever provided or were at that time providing primary Home Based Care for PLWHA.

\subsection{SAMPLE SIZE}

The following formula was used to calculate the sample size.

$$
\mathrm{n}=\frac{\mathrm{Z}^{2}}{\underline{P}(1-\mathrm{P})}
$$

Where;

n- Sample size

E -The standard error in this study, set at 5\%

P-proportion of practice of Home Based Care among family caregivers for PLWHA in the target population is estimated to be $92.8 \%$ (Tibebu et al, 2007).

Z- The standard normal deviation, set at 1.96

\section{Substituting;}

$\mathrm{n}=(\underline{1.96)})^{2} \underline{\mathrm{x} 0.928(1-0.928)}$

$$
0.05^{2}
$$

$=103$

Therefore the sample size used was 103 family caregivers..

\subsection{SAMPLING PROCEDURE}

Convenience sampling was used in recruiting the family caregivers who had ever provided or were at that time providing home based care to PLWHA in order to get the participants. Participation in the study was on voluntary basis in which the information for participation and significance of the study to each participant were provided orally and by signing the informed consent form. This work was performed in 
collaboration with employed HBC coordinator and home care providers for PLWHA one in each street from Ukonga Field force dispensary.

\subsection{DATA COLLECTION TOOLS}

\section{Questionnaire}

The family caregivers were interviewed by filling in a structured questionnaire in Kiswahili language which consisted of 14 questions. 6 questions were for exploring the demographic personal data of the respondents and 11 questions for exploring the believed knowledge, attitude and practice of Home Based Care among the respondents.

Data analysis

Data was analyzed by using Epi-info version 3.4 computer package. The descriptive analysis was performed in which frequency, mean, mode, variance, tables, percentages and Chi square were used.

\subsection{RESULTS}

Family Care givers who participated in this study were 103. $73(71 \%)$ were female and 30( 29\%) were male from nine streets at Ukonga ward. The ages of the care givers ranged between 20 and 72 years (mean age of 38.1 years) as shown on the table 1 below. Majority of respondents were married (61\%), self employed (62\%) and primary school leavers $(56 \%)$. The respondents were grouped into two groups: those who had attended HBC training $(\mathrm{n}=28)$ with mean age of 40.4 years and those who had not attended HBC training $(n=75)$ with a mean age of 37.3 years. Of the respondents who had attended training, $79 \%$ were female and $21 \%$ were male while of those who had not attended training, $68 \%$ were female and $32 \%$ were male. See the table 1 below

\section{Table 1. Respondents' Demographic Characteristics}

\begin{tabular}{|c|c|c|c|}
\hline Variable & $\begin{array}{l}\text { Attended HBC training } \\
(\mathrm{n}=28)\end{array}$ & $\begin{array}{l}\text { Had not attended HBC training } \\
(\mathrm{n}=75)\end{array}$ & $\begin{array}{l}\text { Total } \\
\mathrm{N}=103\end{array}$ \\
\hline Mean age & 40.4 & 37.3 & 38.1 \\
\hline Occupation & $\%(\mathrm{n})$ & $\%(\mathrm{n})$ & $\%(\mathrm{n})$ \\
\hline Employed & $29 \%(8)$ & $13 \%(10)$ & $17 \%(18)$ \\
\hline Self-employed & $57 \%(16)$ & $64 \%$ & $62 \%(64)$ \\
\hline Student & $0 \%(0)$ & $5 \%(4)$ & $5 \%(5)$ \\
\hline Housewife & $14 \%(4)$ & $17 \%$ & $17 \%(17)$ \\
\hline \multicolumn{4}{|l|}{ Sex } \\
\hline Female & $79 \%(22)$ & $68 \%(51)$ & $71 \%(73)$ \\
\hline Male & $21 \%(6)$ & $32 \%(24)$ & $29 \%(30)$ \\
\hline
\end{tabular}




\begin{tabular}{|c|c|c|c|}
\hline Variable & $\begin{array}{l}\text { Attended HBC training } \\
(\mathrm{n}=28)\end{array}$ & $\begin{array}{l}\text { Had not attended } \mathrm{HBC} \text { training } \\
(\mathrm{n}=75)\end{array}$ & $\begin{array}{l}\text { Total } \\
\mathrm{N}=103\end{array}$ \\
\hline \multicolumn{4}{|l|}{ Marital status } \\
\hline Single & $29 \%(8)$ & $43 \%(32)$ & $39 \%(40)$ \\
\hline Married & $71 \%(20)$ & $57 \%(43)$ & $61 \%(63)$ \\
\hline \multicolumn{4}{|l|}{ Education level } \\
\hline Primary & $36 \%(10)$ & $64 \%(48)$ & $56 \%(58)$ \\
\hline Secondary & $58 \%(14)$ & $25 \%(19)$ & $32 \%(33)$ \\
\hline College/university & $7 \%(2)$ & $7 \%(5)$ & $7 \%(7)$ \\
\hline Others & $7 \%(2)$ & $4 \%(3)$ & $7 \%(7)$ \\
\hline \multicolumn{4}{|l|}{ Residence ( street) } \\
\hline Kichangani & $14 \%(4)$ & $13 \%(10)$ & $14 \%(14)$ \\
\hline Gongo la Mboto & $4 \%(1)$ & $11 \%(8)$ & $9 \%(9)$ \\
\hline MadafuUkonga & $14 \%(4)$ & $23 \%(17)$ & $20 \%(21)$ \\
\hline Mazizini & $18 \%(5)$ & $15 \%(11)$ & $16 \%(16)$ \\
\hline MikoroshiniMadafu & $4 \%(1)$ & $3 \%(2)$ & $3 \%(3)$ \\
\hline MombasaMadafu & $7 \%(2)$ & $8 \%(6)$ & $8 \%(8)$ \\
\hline Mongo la Ndege & $7 \%(2)$ & $11 \%(8)$ & $10 \%(10)$ \\
\hline MwembeMadafu & $21 \%(6)$ & $0 \%(0)$ & $6 \%(6)$ \\
\hline Ulongoni & $11 \%(3)$ & $17 \%(13)$ & $16 \%(16)$ \\
\hline
\end{tabular}

\section{BELIEVED KNOWLEDGE OF HBC FOR PLWHA AMONG FAMILY CARE GIVERS:}

Among the respondents, $17(17 \%)$ believed that they were knowledgeable about PLWHA whereas $65(63 \%)$ believed they had inadequate knowledge and 21(20\%) believed they had no knowledge about HBC for PLWHA. 15(54\%), 12(43\%), 1(4\%) of those who attended HBC training $(n=28)$ believed that they were knowledgeable, had inadequate knowledge, and had no knowledge respectively while of those who had not attended HBC training ( $\mathrm{n}=75), 2(3 \%)$ believed they were knowledgeable, 73(71\%) had inadequate knowledge and $20(27 \%)$ had no knowledge. These results showed that there was a difference in believed knowledge between trained and untrained respondents. This was statistically supported $(\mathrm{P}<0.001, \mathrm{P}=0.0096$ and $\mathrm{P}=0.0206$ for those who believed they were knowledgeable, had less knowledge and had no knowledge respectively). Participants reported that they had provided the following kinds of care: $77(70 \%)$ provided physical support, 94(91\%) psychosocial support, 90(87\%) 
palliative care and $83(81 \%)$ spiritual support as is shown on the table 2 below.

Table 2. Respondents' believed knowledge of Home Based Care for People Living With HIV/ AIDS (PLWHA)

\begin{tabular}{|c|c|c|c|c|}
\hline HBC Knowledge for PLWHA & $\begin{array}{l}\text { Attended } \\
\text { HBC } \\
\text { training }\end{array}$ & $\begin{array}{l}\text { Have not } \\
\text { attended HBC } \\
\text { training }\end{array}$ & $\begin{array}{l}\text { Total } \\
\%(\mathrm{n})\end{array}$ & P-Value \\
\hline I believe I am knowledgeable & $54 \%(15)$ & $3 \%(2)$ & $17 \%(17)$ & $<0.001$ \\
\hline $\begin{array}{l}\text { I believe I have inadequate } \\
\text { knowledge }\end{array}$ & $43 \%(12)$ & $71 \%(53)$ & $63 \%(65)$ & 0.0096 \\
\hline $\begin{array}{l}\text { I believe I don't have any } \\
\text { knowledge }\end{array}$ & $4 \%(1)$ & $27 \%(20)$ & $20 \%(21)$ & 0.0206 \\
\hline \multicolumn{5}{|l|}{ Care provided } \\
\hline Physical support & $79 \%(22)$ & $67 \%(50)$ & $70 \%(72)$ & 0.2435 \\
\hline Psychosocial support & $93 \%(26)$ & $91 \%(68)$ & $91 \%(94)$ & 0.7274 \\
\hline Palliative care & $86 \%(24)$ & $88 \%(66)$ & $87 \%(90)$ & 0.7571 \\
\hline Spiritual support & $89 \%(25)$ & $77 \%(58)$ & $81 \%(83)$ & 0.1745 \\
\hline
\end{tabular}

\section{FAMILY CARE GIVERS' HBC ATTITUDE FOR PLWHA}

Of the 103 respondents, 86(83\%)believed that home is a better place than hospital for caring for PLWHA, while only 17(17\%) believed that hospital is a better place than home for caring for PLWHA. Apart from that, 26(93\%) of those who attended HBC training reported that home is better place than hospital for caring for PLWHA while $82(80 \%)$ of respondents who had not attended HBC training reported the same. The respondents reported that $87(84 \%)$ provided care whenever necessary, and $33(32 \%)$ provided care to their friends as shown in the Table 4 below.

Table 4. Respondents' attitude of Home based care for people living with HIV/AIDS

\begin{tabular}{|c|c|c|c|}
\hline $\begin{array}{l}\text { Family caregiver's attitude on HBC } \\
\text { for PLWHA }\end{array}$ & $\begin{array}{l}\text { Attended HBC training } \\
(\mathrm{n}=28) \\
\%(\mathrm{n})\end{array}$ & $\begin{array}{l}\text { Have not attended } \\
\text { HBC training } \\
(\mathrm{n}=75) \%(\mathrm{n})\end{array}$ & $\begin{array}{l}\text { Total } \\
\%(\mathrm{n})\end{array}$ \\
\hline $\begin{array}{l}\text { Believe that home is a better } \\
\text { place than hospital }\end{array}$ & $93 \%(26)$ & $80 \%(60)$ & $83 \%(86)$ \\
\hline $\begin{array}{l}\text { Believe that hospital is a better } \\
\text { place than home }\end{array}$ & $7 \%(2)$ & $20 \%(15)$ & $17 \%(17)$ \\
\hline
\end{tabular}




\begin{tabular}{|l|l|l|l|l|}
\hline \multicolumn{2}{|l|}{ Time taken in caring per day } & & & \\
\hline \multirow{2}{*}{} & All 24 hours & $4 \%(1)$ & $5 \%(4)$ & $5 \%(5)$ \\
\cline { 2 - 5 } & 12 hours only (day/night time) & $7 \%(2)$ & $11 \%(8)$ & $10 \%(10)$ \\
\cline { 2 - 5 } & Provided whenever necessary & $89 \%(25)$ & $83 \%(62)$ & $84 \%(87)$ \\
\hline Relationship with care recipient & & & \\
\hline \multirow{2}{*}{ My brother/sister } & $25 \%(7)$ & $23 \%(17)$ & $23 \%(24)$ \\
\cline { 2 - 5 } & My child & $11 \%(3)$ & $7 \%(5)$ & $8 \%(8)$ \\
\cline { 2 - 5 } & My wife/husband & $14 \%(4)$ & $23 \%(17)$ & $20 \%(21)$ \\
\cline { 2 - 5 } & My parent & $4 \%(1)$ & $13 \%(10)$ & $11 \%(11)$ \\
\cline { 2 - 5 } & My friend & $43 \%(12)$ & $28 \%(21)$ & $32 \%(33)$ \\
\cline { 2 - 5 } & Others & $4 \%(1)$ & $7 \%(5)$ & $6 \%(6)$ \\
\hline
\end{tabular}

Table 5. Relationships of believed attitude of $\mathrm{HBC}$ among family care givers and Hospital readmission of PLWHA.

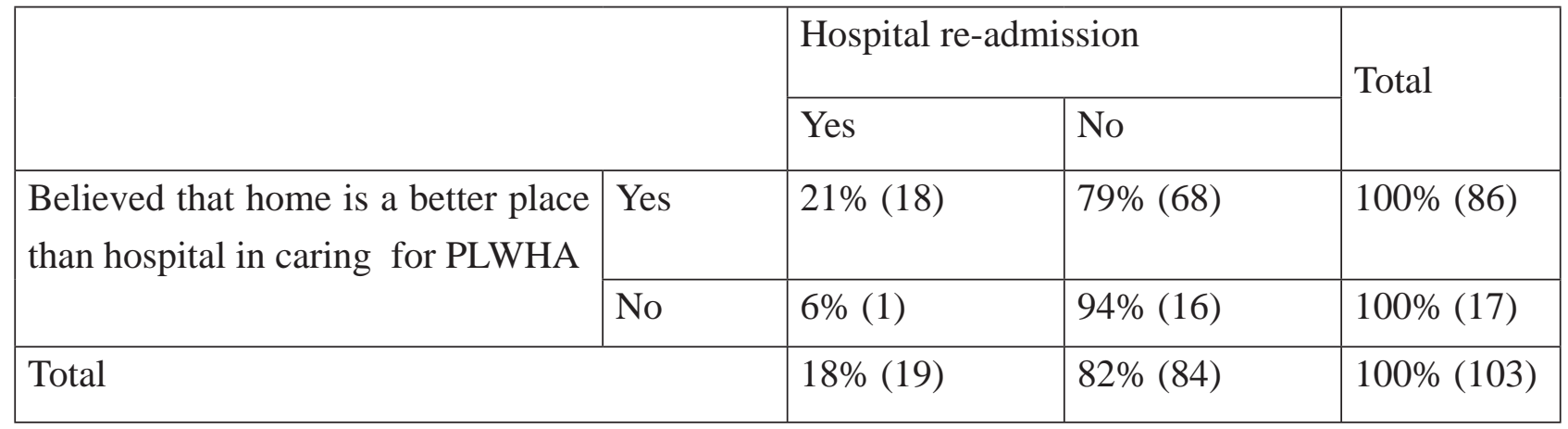

Chi square $\left(\mathrm{X}^{2}\right)=1.2533$, degree of freedom $=1$ and $\mathrm{P}-$ Value $=0.2629$

Hence the relationship of poor HBC attitude (preferred hospital than home) among family care givers and hospital re-admission of PLWHA is statistically not supported.

\section{FAMILY CAREGIVER'S PRACTICE OF HBC FOR PLWHA}

Fifty three of the respondents reported to have good practice of Home Based Care (provided all 4 components such as physical, psychosocial, palliative and spiritual support), $42 \%$ with moderate practice (provided 2-3 components mentioned above) and 5\% with poor practice (provided only one component). Of the HBC trained respondents, 63(61\%) had good practice, 37(36\%) had moderate practice and $4(4 \%)$ had poor practice while of the respondents who had not attended training, $51 \%$ had good practice, $44 \%$ had moderate practice and $5 \%$ had poor practice. Apart from that, the respondents reported that hospital re-admission of PLWHA was because of inadequate services (34\%), poor services (18\%), preference by patients (29\%) and they did not know (19\%) as is shown on the table 6 below. 
Table 7. Relationship of HBC practiced among family care givers and hospital re-admission of PLWHA

\begin{tabular}{|l|l|l|l|l|}
\hline \multicolumn{2}{|c|}{} & \multicolumn{2}{|l|}{ Hospital re-admission } & \multirow{2}{*}{ Total } \\
\cline { 3 - 4 } & Yes & No & \\
\hline \multirow{2}{*}{ Poor HBC practiced } & Yes & $20 \%(1)$ & $80 \%(4)$ & $100 \%(5)$ \\
\cline { 2 - 4 } & No & $18.4 \%(18)$ & $81.6 \%(80)$ & $100 \%(98)$ \\
\hline Total & $18.4 \%(19)$ & $81.6 \%(84)$ & $100 \%(103)$ \\
\hline
\end{tabular}

Chi square $\left(\mathrm{X}^{2}\right)=0.2492$, degree of freedom $(\mathrm{df})=1, \mathrm{P}$-Value $=0.61762$ (Yates' correction 2-tailed p)

Hence the relationship of poor HBC practiced by family care givers and hospital re-admission of PLWHA was statistically not supported.

\subsection{DISCUSSION}

\section{BELIEVED KNOWLEDGE OF HBC FOR PLWHA AMONG FAMILY CARE GIVERS}

The present study indicates that of the 103 respondents, $17 \%$ believed they were knowledgeable, $63 \%$ had inadequate knowledge and $20 \%$ had no knowledge of HBC for PLWHA. However majority of trained family caregivers for PLWHA were more knowledgeable on HBC provision (54\%) as compared to those who had not attended the training $(2.7 \%)$ and this difference was statistically supported $(\mathrm{P}<0.001)$. All study groups of HBC for PLWHA reported that they had provided all or few components of support such as physical support, psychosocial support, palliative support and spiritual support to their patients. The findings revealed that there were no significance relationships of hospital re-admission and believed knowledge among family care givers for PLWHA $(\mathrm{P}=0.803, \mathrm{P}=$ 0.603 and $\mathrm{P}=0.479$ for those who believed that they were knowledgeable, had inadequate knowledge and had no knowledge respectively). The findings of this study are similar to the result of the study done in South Africa which found that there was low knowledge of Home Based Care among family care givers for PLWHA as evidenced by the substantial proportion of caregivers who wished to receive more information and education on caring for people living with HIV/AIDS (11). Another study done in Malawi on knowledge and practice of primary care givers regarding home based care of HIV/ AIDS children revealed a gap/lack of knowledge (10). However the study done in Ethiopia found different results in which family care givers for PLWHA reported to be knowledgeable on HBC provision ${ }^{(12)}$.

\section{FAMILY CARE GIVERS' HBC BELIEVED ATTITUDE FOR PLWHA}

The results of this study revealed that 85 (83\%), which is the majority of the respondents who participated in the study reported that home is a better place than hospital in caring for PLWHA while only17 (17\%) reported that hospital was the better place in caring for PLWHA. There was no significant difference between the groups in their believed attitude towards HBC $(93 \%$ of those who attended training and $80 \%$ of those who had not attended training believed home to be better). Finally the results also revealed that 
there were no significant relationships of believed poor attitude of HBC among caregivers and hospital re-admission of PLWHA ( $\mathrm{P}=0.2629)$. The findings from this study are supported by the study done in Ethiopia which showed that 92.8\% agreed that home is a better place for the care of PLWHA than hospital (12). Also, a survey done in Tanzania in 2003-2004 reported a lot of community willingness to take care of PLWHA: $88 \%$ of females and $90 \%$ of males say they would be willing to provide such care ${ }^{(9)}$. The study done in South Africa showed different results in which the family members expressed a negative attitude toward home based care for PLWHA (13).

\section{FAMILY CAREGIVERS PRACTICE OF HBC FOR PLWHA}

The results of this study revealed that majority of respondents $(53 \%)$ reported that they had good practice of Home Based Care for their patients $(61 \%$ of trained respondents and $51 \%$ of untrained respondents). Apart from that, the relationship of poor practice of Home Based Care and hospital re-admission of PLWHA was statistically not supported $(\mathrm{P}=0.61762)$. This result is supported by the results of the study done in South Africa which showed that almost all caregivers indicated that care giving in the home is not that different from nursing work (providing physical, psychosocial, palliative and

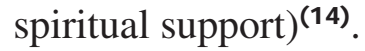

\subsection{CONCLUSION AND RECOMMENDATIONS}

The study highlighted that majority of family care givers have inadequate knowledge, good attitude and practice of the HBC provision. Trained family care givers were observed to be more knowledgeable, have better attitude and practice of home care.

Therefore, HBC Training was observed to be important for family members who are taking care of their relatives living with HIV/AIDS. The importance of the training was shown to help the family care givers in home based care provision as is shown in those who had attended training being more knowledgeable than those had not attended training. Hence the health policy should stipulate the HBC training programs, support network and activities to be performed on the patients (PLWHA) by the family care givers, as well as a sustainable process of identifying and providing necessary requirements as needed for the care of the patients.

Furthermore studies should be conducted in order to explore reasons for the increase in hospital re-admission of PLWHA in developing countries like Tanzania.

\subsection{REFERENCES:}

1 WHO. (2002). Policy Framework for Community Home-Based Care in Resource Limited Settings: Geneva.

2 Mohammad, N. \&Gikonyo, J. (2005). Operational Challenges. Community Home Based Care for Multi-country HIV/AIDS Programs for Sub- Saharan Africa. Africa Region Journal, 88, 1-55

${ }^{3}$ MacNeil, J.M. (1996).Use of culture care theory with Buganda women as AIDS caregivers. Journal of Transcultural Nursing, 7(2), 14-20.

${ }^{4}$ AIDS Policy Research Center. (2004). Country AIDS Policy Analysis Project: HIV/AIDS in Tanzania

5 Kipp, W., Tindyebwa, D.,Rubaale, T., Karamagi, E.,Bajenja, E. (2006). Family Care giving to AIDS patients: The Role of Gender in Caregiver Burden in Uganda.Journal of International Women's Studies, 7, 1-13.

${ }^{6}$ Akintola, O. (2004).A gendered analysis of the burden of care on family and volunteer caregivers 
in Uganda and South Africa.

${ }^{7}$ Tarimo, A.M., Kohi, W., Outwater, A., Blystad, A. (2009). Gender Roles and Informal Care for Patients with AIDS.Journal of Transcultural Nursing, 20, 61-68.

${ }^{8}$ WHO. (2000). The Comprehensive Continuum of Care: Key Elements in Care, Treatment and Support.

${ }^{9}$ Tanzania HIV Indicator Surveys 2003-2004.

${ }^{10}$ Zimba, E. W., \&McInerney, A. (2001). The knowledge and practice of primary care givers regarding home-based care of HIV/AIDS patients in Blantyre (Malawi). Curationis, 24, 83-91.

${ }^{11}$ Horman, R., Searle, C., Williams, E., Mafata, S., Meidany, F., Oosthuizen, C., Towel, L. (2005). Exploring the role of family caregivers and home-based care programsin meeting the needs of people living with HIV/AIDS," Horizons Research Update. Johannesburg: Population Council.

${ }^{12}$ Tibebu, B., Mariam, A., Balachew, T. (2007). Knowledge, attitude and practice of home based care for HIV/AIDS patients by their family/ caregivers at Jimma town. Ethiopia med. J. 45(3): 283-92.

${ }^{13}$ Tshililo, A., Maselesele, M. (2009). Family experiences of home caring for patients with HIV/AIDs in rural Limpopo Province, South Africa; Nursing \& Health Sciences, 11(2), 13543).

${ }^{14}$ Hunter, N. (2007). "It's like giving birth to the sick person for the second time" Working Paper No 44 (ISBN 978-1-86840-604-3). South Africa 